\title{
A Study of Linguistic Politeness in Japanese
}

\author{
Xiangdong Liu'1, Todd James Allen² \\ ${ }^{1}$ University of Western Sydney, Sydney, Australia \\ ${ }^{2}$ University of Queensland, Brisbane, Australia \\ Email: x.liu@uws.edu.au, t.allen2@uq.edu.au
}

Received 27 September 2014; revised 18 November 2014; accepted 27 November 2014

Copyright (C) 2014 by authors and Scientific Research Publishing Inc.

This work is licensed under the Creative Commons Attribution International License (CC BY). http: //creativecommons.org/licenses/by/4.0/

(c) (i) Open Access

\section{Abstract}

This paper re-examines theories of linguistic politeness in Japanese, and holds that linguistic politeness is a very complicated issue influenced by multiple factors in different layers including general face wants of participants, the participants' societal positions and social relationships, social norm that the interactants share, the interactants' discernment or interpretation of the social rules, immediate context of the interaction, and possible strategies for the interactants to choose under the constrains of the other simultaneously functioning factors. Based on the data collected from recent Japanese TV dramas, this study maintains that, as a general principle, Brown and Levinson's $(1978,1987)$ theory of face does apply to Japanese language and culture and forms the base of politeness. Similarly as in any other culture, facework in successful communication in Japanese is a result of choice by an interlocutor in accordance with normative polite practices. What makes linguistic politeness in Japanese unique is not that Japanese speakers need to act appropriately according to their social norm, but that their discernment (wakimae) and recognition of the social position and relationship (tachiba) of the participants, which form the second layer of the determining factors of politeness, make speakers of Japanese always attend to and try to fulfil the other participant's face want including both positive and negative face, and, at the same time, maintain their own positive face but rarely claim their own negative face especially when an interactant has less power and in a lower social position in an interaction. The data also suggest a model of face-redressing strategies co-occurring with face threatening acts (FTA) in Japanese.

\section{Keywords}

Politeness, Japanese, Face, Face Threatening Act (FTA)

\section{Introduction}

Linguistic politeness has been a hot topic since the landmark study by Brown and Levinson (1978, 1987) (B \& L henceforth) who proposed the theory of universal politeness central to which is their discussion on "face". While 
some researchers question and challenge the universality of B \& L's politeness theory based on investigations of language use especially in non-Western cultures (Hill, Ide, Ikuta, Kawasaki, \& Ogino, 1986; Ide, 1989, 1992; Mao, 1994; Matsumoto, 1988, 1989), some others attempt to defend the universal applicability of B \& L's theory or present different views utilizing B \& L's analytical model as a heuristic device (Cook, 2006; Fukada, 2007; Fukada \& Asato, 2004; Gagné, 2010; Ishiyama, 2009; Pizziconi, 2003). Motivated and necessitated by the ongoing debate as to whether or not B \& L's theory of universal politeness accurately describes the Japanese language and culture, this study aims to reassess the theories put forth by previous studies, and identify whether or not and how linguistic politeness in Japanese is unique. Drawing on the data, this study claims that B \& L's theory of face does apply to Japanese language and culture, and that the uniqueness of politeness in Japanese is that Japanese speakers rarely claim their own negative face especially when an interactant has less power and in a lower social position in an interaction, while they, as people in other cultures, always attend to and try to fulfil the other participant's face wants including both positive and negative face, and, at the same time, maintain their own positive face. This study also proposes a model of face-redressing strategies co-occurring with face threatening acts (FTA) in Japanese.

Before we attempt to deconstruct linguistic politeness in the Japanese context, it must be pointed out that the debate over the term "politeness" continues, with scholars struggling to create and agree on a suitable and consistent definition for the term (Kasper, 1990; Lakoff, 1975; Leech, 1983; Sifianou, 1992). Brown and Levinson (1987: p. 13) describe politeness in universal terms as "a complex system for softening threats". On the other hand, Hill et al. (1986: p. 349) define politeness in a more Japanese cultural-specific sense as "one of the constraints on human interaction, whose purpose is to consider others' feelings, establish levels of mutual comfort and promote rapport”. Although this paper investigates Japanese politeness phenomena, it does not attempt to continue the debate of a suitable or universal definition of politeness. Instead, by highlighting the various definitions of politeness here, it creates a sense of what politeness is within the linguistic framework, draws attention to the fact that defining politeness is a challenging task and an ongoing debate, and adds further information in regards to Japanese politeness to already established theories.

While analysing the data, this paper also takes into consideration societal concepts of Superior v. Inferior and Inside v. Outside, which are very important in understanding Japanese culture. The concepts of Superior (目上 теue) and Inferior (目下 meshita), plays an integral role in all social relationships such as those in school, workplace and sporting environments, to mention a few. These concepts have a large influence in the way Japanese speakers communicate and socially behave, and shape the societal and cultural norms which interactants heavily rely on, giving cues to one another about what is acceptable and what is not during an interaction. Not only does Japanese society work within a hierarchy system but also within an inside and outside relational system. The term Inside (内 uchi) refers to an interactant's inner social circle such as close friends, family members and co-workers, while Outside (外 soto) refers to an interactant's outer circle relations such as people belonging to different social groups. It must be noted here that these relationships or positions are dynamic and change continually depending upon situation and context.

Politeness in Japanese is largely determined by the above-mentioned relationships within the hierarchy and inside-outside systems. Interactants need to always make a choice for a proper linguistic form, which properly reflects the speaker's position within the systems as well as the actual context of the communication. Based on this understanding of the Japanese culture and society, this paper will provide answers to the following research questions:

1) Is B \& L's definition of Face applicable to Japanese?

2) What are determining factors in analysing politeness in Japanese?

3) Does the Japanese language fit into the same Face Threatening Act (FTA) process that B \& L $(1978,1987)$

claimed in their politeness model?

This paper consists of 6 sections. In Section 2, we discuss the main contents of B \& L's politeness theory, followed by Section 3, where some of the most influential work on linguistic politeness in Japanese are presented. In Section 4, we give explanations and justification of the data set and steps of the investigation of this study. Section 5 exemplifies the claim of this study regarding face, and FTA in Japanese, and the final section presents the conclusion.

\section{B \& L's Politeness Theory}

B \& L's $(1978,1987)$ theory of politeness, which they deemed to be universal across all cultures and languages, 
is centred upon discussions on Face, facework and Face Threating Acts (FTA).

\subsection{Face}

According to B \& L (1987: pp. 2, 61-62), face is an individual's self-esteem or "the public self-image that every member wants to claim for himself”. It consists of two related aspects: negative face and positive face. Negative face is "the basic claim to territories, personal preserves, rights to non-distraction-i.e. to freedom of action from imposition". In other words, negative face is "the want of every competent adult member that his actions be unimpeded by others". Negative face defined by B \& L extends to create a meaning in politeness that reflects non-imposition. Positive face, on the other hand, is defined as "the positive consistent self-image or 'personality' (crucially including the desire that this self-image be appreciated and approved of) claimed by interactants". It is "the want of every member that his wants be desirable to at least some others", That is, individuals want others to recognise their achievement of their goals, ambitions or possessions, they expect people relevant to their achievements to acknowledge their ability of achieving their goals, but not by any others. B \& L's theory of positive face creates an idea of the wants of an individual reflecting more than just those of material things. Love, hate, greed, sadness are also examples of wants reflected in positive face. B \& L state that aspects of face are "basic wants, which every member knows every other member desires, and which in general is in the interests of every member to partially satisfy”. They maintain that for face to fully function in discourse is for interactants (both hearer and speaker) to maintain both their own face and the face of others. This is what B \& L termed "mutual vulnerability of face", whereby "people cooperate (and assume each other's cooperation) in maintaining face in interaction". B \& L also make note that face is treated like the zweckrational model in the sense that face is something that can be overlooked or ignored as in the case of emergency, directness or cooperation, and although in the individual's best interests, an interactant does not have to adhere to another persons' face wants.

B \& L point out that the notion of a speaker's "wants" are "highly culture-specific, group-specific, and ultimately idiosyncratic" (1987: p. 64), and claim that while the cultural value of face itself may differ, the "want" to understand and "satisfy members" public self-image or face, and the social necessity to orient oneself to it in interaction are universal (1987: p. 62).

\subsection{Face Threatening Act (FTA)}

The concept of Face Threatening Acts (FTA) is another main part of B \& L's politeness theory. B \& L define an FTA as a particular type of verbal or non-verbal performance that is contrary to the definitions of face. In other words, it is an act that is against the want of the speaker and/or hearer. According to B \& L, FTAs are both intrinsic and extrinsic. In order to achieve the communicative purpose, speakers need to choose to either perform or avoid FTAs. Unless a speaker during discourse wants to complete an FTA with maximum efficiency, generally the speaker will choose an appropriate face-redressing strategy to protect the hearer's (and speaker's) face and to minimize the amount of force of the FTA by balancing three wants: "(a) the want to communicate the content of the FTA x, (b) the want to be efficient or urgent, and (c) the want to maintain the hearer's face to any degree. Unless (b) is greater than (c), the speaker will want to minimize the threat of [the] FTA" (B \& L, 1987: p. 68). The possible strategies summarised by B \& L are as shown below (Figure 1).

According to B \& L, an FTA could be either "on record" or "off record". The term "on record" refers to an act of an interactant completing an utterance that is understandable and unambiguous to both interactants. The

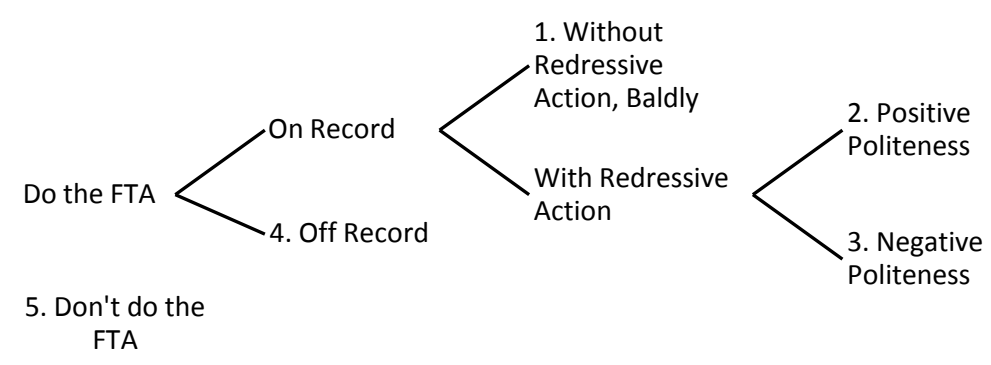

Figure 1. Possible strategies for doing FTAs (B \& L, 1987: p. 69). 
first on record FTA strategy, "Without redressive action, Baldly", refers to FTAs completed in a "direct, clear, unambiguous and concise way possible" for completing an FTA, and the example that B \& L provides is a request "Do X!". This type of FTA will be successful only if the speaker does not concern himself/herself with the ramifications of his/her utterance. That is, if both parties agree that the notion of face and politeness to be put on hold for the sake of urgency (1987: p. 69). B \& L also describe two other scenarios whereby the speaker can act so baldly. One of them is "where the danger to the hearer's face is very small, as in offers, requests, suggestions that are clearly in the hearer's interest and do not require great sacrifices of the speaker", and the other "where the speaker is vastly superior in power to the hearer" (1987: p. 69).

B \& L labels the second and third on record FTAs as "with redressive actions", and note that "redressive action" generally "gives face" to the hearer within an utterance, and attempts to counter balance the potential damage an FTA can produce. They describe this type of action as a cushion to the upcoming FTA, and displays that the speaker is aware of the face wants of the hearer. This type of strategy takes the form of either attending to the positive face of the hearer (i.e., positive politeness) or protecting the negative face of the hearer (i.e., negative politeness) (B \& L, 1987: p. 70). B \& L maintains that positive politeness has an element of in-group attachment to particular utterances, and shows the hearer that the speaker only wants some of the hearer's wants, and the speaker moves towards showing that they are similar in the particular situation based upon "in-group rights and duties and expectations of reciprocity, or by the implication that the speaker likes the hearer so that the FTA doesn't mean a negative evaluation in general of the hearer's face” (B \& L, 1987: p. 70). Negative politeness, on the other hand, is seen as an action of not interfering with the speaker's right to action and upholding his/her right to be unimpeded. It is seen as a way for the hearer to escape so to speak and for both parties to "save-face". It is often linguistically accompanied with an apology or redress. In the example "can you pass the salt?” (1987: 70), B \& L claim that there are situations where "there is natural tension in negative politeness, however, between (a) the desire to go on record as a prerequisite to being seen to pay face, and (b) the desire to go off record to avoid imposing”. Both interactants come to a "conventionalised indirectness", in which allows for an FTA to be understood and implied without being confused.

The other side of the coin occurs when an interactant "goes off record". When this type of strategy is applied, the utterance is generally ambiguous in order for the interactant to not be held responsible for a particular intention of a future act. B \& L provide an example: "Damn, I'm out of cash, I forgot to go to the bank today". This example highlights that the speaker (despite the use of a hint) cannot be held accountable for the actions of the hearer. B \& L also indicate that these "off-record strategies include metaphor and irony, rhetoric questions, understatement tautologies” (1987: p. 69).

The strategies summarised by B \& L are observed in the data of this study where some characteristics seem to be unique in Japanese language. Details are discussed in Section 4 and an FTA model in Japanese is also proposed in that section.

\section{Previous Studies of Politeness in Japanese}

B \& L's theory of face and FTA (face threatening acts) have been challenged or have suggested modifications to the universal claim by several scholars. As a result, these challenges and suggestions have stirred debate, especially on the notion of negative face among researchers of Japanese language who emphasis that Japanese culture is unique.

One of the most widely known studies is by Ide (1982), who introduced the notion of wakimae or discernment. The term was re-introduced by Hill et al. (1986) in a comparison study that quantitatively investigated linguistic politeness in Japanese and English. Hill et al. believes that the fundamental factor of politeness in Japanese is the interactants' wakimae or discernment rather than their face wants, and that including the idea of discernment and its counter part volition allows a better description when characterizing sociolinguistic systems of politeness in different cultures and languages. Hill et al. (1986: p. 348) describe wakimae or discernment as "the almost automatic observation of socially-agreed-upon rules" which applies to both verbal and non-verbal behaviour, and "is the most important factor in questions of politeness in the Japanese context". They suggest that a capsule definition would be “conforming to the expected norm” (Hill et al., 1986: p. 348). They further claim that Japanese politeness works on a two fold system, whereby not only is discernment a vital factor, but also the degree to which the interactant actively chooses an agreeable linguistic form "according to the speakers intention". Choosing an agreeable linguistic form is what Hill et al. termed "volition". Hill et al. believe that this is the pinnacle in 
their new claims, and their research results reveal this to be the case (Hill et al., 1986: p. 348).

Another frequently cited work on Japanese politeness is Matsumoto (1988). Matsumoto asserts that B \& L's assumption that all people within a given society have both a negative and positive face is not automatically universal. She claims that the concept of negative face wants are not applicable to Japanese culture:

"What is most alien to Japanese culture in the notion of face, as attributed to the model person, is the concept of negative face wants as the desire to be unimpeded on one's action. Postulating as one of the two aspects of the Model Person's 'face', the desire to be unimpeded, presupposes that the basic unit of society is individual. With such an assumption, however, it is almost impossible to understand behaviour in the Japanese culture" (Matsumoto, 1988: p. 405).

Discussing how formulaic expressions are used as "relation-acknowledging devices", Matsumoto claims that imposing on others is not something that the Japanese try and avoid, but rather choose appropriate linguistic styles which are aimed at the interactant's position. Although B \& L suggest that formulaic expressions are examples of an enhancement of the addressee's face, Matsumoto insists that this is not true for Japanese interactants because of the manner in which these formulaic expressions are expressed, i.e. "not done straight-forwardly" (Matsumoto, 1988: p. 410).

More recently Haugh and Obana (2011: p. 149) suggest that politeness in Japanese is closely related to the notion of tachiba ("the place where one stands"). They define the term tachiba as "the contextually contingent and discursively enacted social roles and positions of participants" and Haugh (2007: p. 660) explains that tachiba encompasses "the interactional achievement of one's public persona or social standing as distinct from others, including one's position or role (ichi, yakuwari), status (mibun, chi'i) and current state or circumstances $(j \overline{\boldsymbol{o}} \mathbf{k y} \overline{\boldsymbol{o}})$ ". Haugh and Obana (2011) further claim that no matter how desirable the addressee's wants are perceived to be, the speaker's tachiba places constraints on their linguistic realisation.

The numerous previous studies into linguistic politeness including B \& L's universal theory and the ones briefly mentioned above represent the accumulated knowledge of linguistic politeness, and all contribute to explanations and descriptions of linguistic politeness in Japanese in one way or another. However, the data set of this study reveals that none of them alone is efficient enough to explicate this very complicated issue, and that facework does play an important role in Japanese language and culture, so do the other factors such as social norms, the interactants' social positions, relationships and the actual context of the interaction, though negative face and positive face are not equally treated by or important to a Japanese speaker. These details are discussed in Section 5.

\section{Data and Methodology}

Since linguistic politeness reflects the speaker's social status and behaviour, the social and linguistic contexts, or in other words, sociocultural and discourse circumstances, are crucial when conducting pragmatic research on politeness. While some previous studies base their discussions on the outcomes of surveys and participants' reflective comments or interviews, bias conclusion have been pointed out (see Cook, 2006; Gagné, 2010). To avoid possible bias outcomes, this study chose recent Japanese dramas as its data set, and believes that dramas are ecologically valid data for the following reasons. First, to be successfully appealing to audiences, dramas are required to exhibit up-to-date characteristics of language use and reflect real situations in people's daily life in the society. Secondly, each actor inserts his or her own style into the dialogue, creating a much more realistic performance, whereby art imitates life as much as possible. Therefore they are one step closer than surveys to naturally occurring speech examples in real conversations. The chosen dramas were created during the period of 2011-2013 presenting the current status of the aspects of language use being investigated.

The dramas examined in this study are entitled Kare, Otto, Otoko Tomodachi ("Boyfriend, Husband, Male Friend", referred to hereafter as KOOT); Gekiryuu ("The Torrent"), and Mayonaka no Panya-san ("Midnight Bakery", referred to hereafter as MB). These dramas afforded this project the chance to analyse and further understand the dynamics of the linguistic behaviour displayed by Japanese interactants influenced by the culture of the society. They allowed the opportunity to analyse Japanese language use in different social contexts, to be precise, personal or intimate settings and vocational formal settings.

As the first step of data analysis, the entire series were viewed to gain an understanding of the contexts in which the linguistic behaviours in question occurred and to understand the characterisation. As the second step, the dramas were re-watched with a focus on confirming appropriate examples of utterances serving the arguments 
of the current study regarding face, face threatening acts, and face-redressing strategies applied when conducting FTAs, with the social relationships (i.e., inside-outside and superior-inferior) and other societal factors in mind. Analysis of the examples based on the criteria focuses on not only the linguistic style but also the effect of the utterance. In other words, we are not only investigating what is actually being said in a particular situation or context, but also why the speaker said it and how it affected the Face of the other interactant(s).

\section{Findings and Discussion}

In analysing the data set, two main points arose to re-examine some existing theories about politeness in Japanese, including B \& L's theory of Universal Politeness, and the theories regarding discernment (wakimae) and place (tachiba). That is, (1) the connection between face, relationship of the interactants, their discernment (wakimae) and their place (Tachiba) in the society; and (2) the redressive strategies of Japanese FTA. These main points extend from ultimately the culture being a driving factor in deciphering politeness situations, and therefore affecting the linguistic output. Based on the data, this study introduces a Japanese FTA model displaying the steps involved in a Japanese FTA.

\subsection{Face in Japanese}

As mentioned when discussing existing theories and claims made by previous studies on Japanese politeness, this study maintains that the discussion on politeness needs to take into consideration multiple factors. It is certainly true that theories and approaches suggested by previous studies provide rich knowledge about and profound insight into issues of linguistic politeness. However, none of them alone can do the work satisfactorily. This study holds that, similar to people of other cultures, Japanese speakers do have face wants. They know that both they themselves and the other interlocutor(s) have positive and negative face wants, that is, people normally want their self-image to be appreciated and approved by others in the society, and they want freedom from imposition. Therefore, they ensure they behave appropriately, both verbally and non-verbally, according to their discernment (wakimae) in understanding the social place and relationship within the social norm (tachiba). The utterances that they choose reflect their relationship as well as the context of the particular interaction. What is unique in Japanese language and culture is that their discernment makes speakers of Japanese always attend to and try to fulfil the other participant's face wants including both positive and negative face, and, at the same time, maintain their own positive face but rarely claiming their own negative face especially when the interactant has less power and is in a lower social position in an interaction. In fact, the face of the interactant who is in a lower position and who has less power in the interaction is quite often ignored.

The first example supporting the claims of this study is seen in KOOT, showing how Haruko, Asako and Kunikawa Tada (Asako's husband) talk to each other in different ways before and when Kunikawa Tada is suffering from extreme amnesia after attempting suicide. It is an excerption of interaction of the three when Harukomeets Kunikawa Tada after the incident and needs to re-introduce herself to him.

(1) 1. Haruko: Konnichiwa.

good-day

"Hello."

2. Tada: Hajimemashite. how-do-you-do

"How do you do?"

3. Haruko: Hajimemashite.

how-do-you-do

"How do you do?"

4. Asako: Tada-san, watashi no imooto desu. (name)-SUF-POL I NML younger-sister COP-POL

"Mr. Tada, this is my younger sister."

5. Tada: Imooto-san. O-shigoto wa? younger-sister-SUF-POLPRE-HON work TOP

"Your younger sister. What is your job?"

6. Haruko: Etto... ibento puranna desu. umm event planner COP-POL 
"Umm... event planner."

7. Tada: Ibento puranna. Sugoi desu ne.

event planner great COP-POL SFP

“Event planner. What a great job that is. [Lit. That is great isn't it?]”

Although in previous scenes Tada has spoken down consistently to his wife (Asako) and wife's sister (Haruko), he uses here hajimemashite (“How do you do?”) in responding to Haruko's greeting in Turn 2; attaches the honorific suffix san to the word imooto ("younger sister") and the honorific prefix $O$ when asking about Haruko’s occupation shigoto (“work”) in Turn 5; and raises up Haruko by saying sugoi ("great”) about her work using the polite form of the copula desu in Turn 7. This change in linguistic behaviour shows that due to his amnesia, Tada does not know with whom he is actually speaking and therefore regards the relationship he has with the other participants in the interaction outside (soto). It also shows that he wants to maintain his positive face, a good self-image, and, for that purpose, chooses the polite and honorific forms to reflect his interpreting of the social relationship following the social rules. On the other hand, the sisters accommodate their speech style to his to maintain his negative face, instead of reminding him after he uttered Turn 2 that he is talking to his wife and sister-in-law and therefore "How do you do" is improper in this situation. The accommodation can be observed from the greeting in Turn 3, Asako's use of the honorific suffix san when addressing her husband, and the polite form of the copula in Turns 4 and 6 . This is totally different from their normal speech style illustrated in Example (2).

(2) 1. Haruko: Kunikawa-san, ishiki ga modotta $n$ da ne. (name)-SUF-POL consciousness NOM recovered AUX COP-PLN SFP

“Kunikawa has regained consciousness, hasn't he?”

Nee, itsu kara?

INT When from.

"From when?"

2. Asako: Tooka hodo mae.

10 days about ago

“About 10 days ago.”

3. Haruko: Sonna ni mae ni?

that PART before PART

"That long ago?"

Nande itte kurenai no?

why speak to-me-NEG-PLN SFP

"Why didn't you tell me?"

Doo suru tsumori na no?

how do plan AUX SFP

"What do you plan on doing?"

4. Asako: Oboetenai no.

remember-CONT-not-PLN SFP.

“[He] doesn't remember [anything].”

5. Haruko: ee?

CAS

"What?"

As can be seen in the above example, the two sisters, Asako and Haruko, normally talk to each other in plain forms ( $d a$ in Turn 1 and nai in Turns 3 and 4) and quite often omit the main verbal of the sentence (as in Turns 1, 2 , and 3). While these utterances are in plain or omitted forms, they are not impolite, as the interaction takes place within an inside relationship (uchi). In addition, although in Example (2) Haruko is asking about the health condition of Asako's husband in a very direct way and blaming Asako for not having disclosed to her family how serious the situation is up until this point, she is not either intending to or being interpreted by Asako as threatening Asako's negative face. The evidence supporting this claim is that Haruko's utterances in fact create a chance for Asako to start an emotional conversation with her family. This example reveals that the factor that determines whether an utterance forms an FTA is not its linguistic form but its communicative function or illocutionary force and the speaker's intention within the social norms. To be precise, in the case of Example (2), the direct questions in plain and omitted forms are uttered for the benefit of the addressee, Asako. They function 
to show the speaker's deep concern about the addressee and the speaker's intention to share the hardness and to help. They also remind the addressee the inside relationship between the two interlocutors. Because they are not FTAs, there is no need for a face-redressing act.

As mentioned at the beginning of this section, face of interactants in a lower social rank can be ignored. Below is an example of an interaction between a senior member and her inferiors at work.

(3) 1. Haruko: Sayuu taishoo ni naru yoo ni o-negai-shimasu.

bilateral symmetry PART become so PART beg-HON

"Please try to make it bilaterally symmetrical."

2. Haruko: Baransu toretenai yo. Moo chotto.

balance get-PRO-NEG-PLNSFP more a-little-bit

"It is not balanced! A little more."

Migi sagete. Motto, motto, motto.

right hang-lower-COL more more more

"Hang the right side down more, a little more, just a little more."

A, sage sugi da yo.

Ah hang-lower too-far COP-PLNSFP

"Ah, it's down too far!"

Ii gurai tte no ga wakannai no?

good about HM NML NOM understand-NEG-COL-PLN SFP

"Don't you know how to make it look right?"

3. Assistant: Sumimasen.

sorry

"I'm sorry."

In this scene, Haruko, an event planner, is directing her inferiors to hang up objects for her. A deconstruction of her utterances displays two forms of linguistic register. She uses a humble form of “please”, o-negai-shimasu, in Turn 1 when issuing instructions to the assistants, but then down-shifts her speech style to non-polite, using plain form of verbs and the copula (i.e., torenai, wakannai, da) and sentences with the main verb omitted (i.e., the first and second lines in Turn 2). Using polite form in Turn 1 signposts the speaker's face management, that is, to nurture the positive face of her own and, at the same time, to mitigate the force of her command, which inturn can maintain the addressees' negative face. In the Japanese culture, it is accepted that less formal language is used and less face-saving work is conducted when speaking to inferiors. Therefore, Haruko is allowed, according to the social rules, to use plain forms, and does not need any strategy to defuse the impact of her direct instructions to save the assistants' negative face. This example illustrates the connection between facework and the hierarchy of relationship and the social rules.

The examples discussed above illustrate that Japanese speakers do attend to face of their own and others depending on their discernment in recognising the relationship and position of the interactants. Without taking into consideration face, choice of linguistic means such as those observed in examples (1), (2) and (3) cannot be adequately explained. These examples also verify that linguistic politeness is realised through multiple factors. To achieve one's face wants, it is important for a speaker to recognise the relationship between the interlocutors (e.g., uchi "inside", soto "outside", meue "superior", meshita "inferior"), the context of the interaction and the social norm shared by the participants in communication. In other words, without paying attention to all these factors simultaneously, we cannot elucidate what is polite or impolite, why direct questions about other's private life in plain form such as those in example (2) function to show intimacy or kindness while some other utterance in polite form could be an FTA. It is based on this view, this study claims that while previous studies provides rich knowledge about and profound insight into issues of politeness, it seems none of them alone could expound linguistic politeness in Japanese.

\subsection{FTA and Face-Redressing Acts in Japanese}

Although some previous studies claim that negative face is alien to the Japanese culture (Matsumoto, 1988: pp. 405-408), examples found in this data set prove that negative face does exist in Japanese culture and is reflected in Japanese language use. If we have to specify any peculiarity of Japanese distinguishing it from other language 
and culture, it will be that people normally do not claim their own negative face, but always perform facework for the other participant's negative face, including using more than one face-redressing expression before and/or after a possible but necessary FTA. In some extreme cases, the FTA itself could be omitted, and only some face-redressing expressions are spoken to imply the real message. Below are some examples. Examples (4) and (5) exemplify face-redressing act before FTA, (6) illustrates facework after an FTA, and (7) represent a case where the FTA itself is omitted and implied by face-redressing express only.

(4) 1. Haruko: Ano sa... ano ne... kekkon tte sa, yappari ii mono?

INT INT INT INT marriage HM INT still good thing

"Well umm... You know... Is marriage really a good thing?"

2. Asako: Dooshita no? Kyuuni.

What-happened SFP suddenly

"Why do you ask? This is all of a sudden."

3. Haruko: Chotto ne. Nanika kekkon ni tsuite tamaniwa shinkenni oshiete miyoo ka na to omotte.

a-little SFP something marriage PART regarding occasionally seriously teach-VCF try-VOL QM SFP HM think-VCF

"Yeah, just a little. I’m just thinking whether I should sometimes try to talk [to him] about marriage with a more serious mind."

4. Asako: Kekkon shitai no? Haruko-chan?

Marriage do-DESID SFP (name)-SUF-COL

"Do you want to get married, Haruko?"

5. Haruko: Iya, jibun mo yoku wakannai n da yo ne.

No myself also well know-NEG-COL COP SFP SFP

"Not sure. I probably don't even know the answer myself."

In Example (4), Haruko visits Asako, her older sister, and asks her opinion about marriage based on her own marital life (Turn 1). The question is personal, and unlike Example (3), it is asked not for the benefit of the hearer, Asako, but to help the speaker herself who is struggling with a decision about marriage now, a fact that she had never told anyone yet. The question therefore will impose the hearer, Asako, and form an FTA. For this reason, despite the closeness of the relationship between the two, Haruko, following the social rules uses a series of hedges (i.e., ano sa "Well umm...", ano ne "You know...", and ...ttesa "talking about...") before putting what she really wants to know explicitly (i.e., yappari ii mono? "is it really good?"). When answering the question that Asako asked back in Turn 2, Haruko again chooses a rather indirect way of speech in Turn 3 with the form "...kana to omotte", which can be literally translated into English as "I think it might be...". All the expressions used before the main part of the question and those attached to the proposition of the answer in Haruko's utterances are used as cushions to buffer the force of the FTAs. Haruko's linguistic behaviour shows that she does not want to be impolite to lose her own positive face and also threaten Asako's negative face.

(5) 1.Nozomi: A... anoo... Kurebayashi Miwako-san tte hito imasu ka.

Uh INT (name)-SUF-POL HM person is-here QM

"Uh...Excuse me. Is Mrs MiwakoKurebayashi here?"

2. Yosuke: Miwako wa watashi no tsuma desu ga...

(name) TOP I GEN wife COP-POL but

"Miwako is my wife ..."

3. Nozomi: Anoo...Shitsuree desu kedo...

INT rude COP-POL but

"Excuse me... I know it is rude but..."

Miwako-san no danna-san tte kaigai kinmu no sarariiman janai n desu ka.

(name)-SUF-POL GEN husband-SUF-POL HM overseas work GEN company-employee COP-NEG-COL AUX COP-POL QM

"Isn't Miwako's husband a company employee working overseas?"

4. Yanagi: Sore wa mukashi no hanashi.

that TOP past GEN story

"That is a story of the past."

Ima wa kono hito ore no deshi yatteiu kara.

now TOP this person I GEN apprentice doing because 
"Because he is now working as my apprentice."

Kono mise no oonaa ken buranje minarai.

this shop GEN owner and boulanger probationer

"[He is] the owner of this shop and a trainee boulanger."

5. Nozomi: buranje

boulanger

"Boulanger"

6. Yanagi: Pan shokunin

bread maker

"A baker."

7. Nozomi: Pan shokunin. Hanashi chigau shi...

bread maker story different and

“A baker. That's different from what I’ve been told...” [Grumbling to herself]

This is an excerpt from a scene in MB where Nozomi, a high school girl, comes to visit her half-sister Miwako and finds that the address on the envelope of the letter from Miwako is a bakery. She started the conversation with anoo, an interjection expressing hesitation or discretion of the speaker, before asking the question in Turn 1. She has been told that Miwako's husband is working overseas for his company. Therefore, she thinks something must be wrong when Yosuke says that Miwako is his wife in Turn 2. However, Nozomi does not want to behave impolitely to lose her positive face nor impede on Yosuke's face. At the same time, there is certainly a need for her to find out the truth. Based on her recognition of the relationship she has with the other interlocutor (i.e., they are meeting for the first time and Yosuke is older than her), Nozomi chooses to use anoo again followed by shitsuree desu kedo... ("I know it is rude but...”) as buffers before pointing out the discrepancy between information she has been given (Turn 3). In addition, desu, the polite form of the copula, and an indirect negative question style janai $n$ desuka ("isn't it that ...") are also observed in the question in Turn 3. All the buffers and the polite and indirect linguistic forms function to defuse the impact of the question on the listener's face, and also serve the facework of the speaker, and reflect the speaker's recognition of social rules and the relationship between the participants in the conversation.

(6) Misumi: Saba wa sa dooshite rikonshita no?

(name) TOP INT why divorced-PLN SFP

"Saba, why did you get a divorce?"
A. Gomen, henna koto kiite.
oh sorry-COL strange thing ask-VCF
"Oh, sorry for this strange question."

This is an example that occurred in the drama Gekiryuu ("The Torrent”). The interlocutors of this conversation are Misumi and Sabashima, who were very good friends during high school. After meeting on a bullet train by chance twenty years after graduation, they become close again. Example (6) is a conversation between the two when they meet for the third time after reunion. Misumi tells Sabashima that her husband wants to divorce her and that things at work are not going well either, and then asks Sabashima why he wanted a divorce. The speech style is an inform one alone with the usage of plain and incomplete forms of verbs (i.e., rikonshita "divorced” and kiite "asking”), the listener's nickname Saba (instead of his full name with a polite suffix, e.g., Sabashima-san), and the word gomen, a colloquial version of "sorry". As (6) shows, Misumi apologises right after her question about Saba's divorce, before he says a word. This indicates that Misumi knows that a question about one's private life could threaten one's negative face, and that a member of the Japanese society should not make others feel embarrassed or put them in trouble. That is, face-respect toward the addressee is especially important in most situations. Caring about the participant's face, Misumi chooses to add the facework after the question to mitigate the FTA. The linguistic forms and the facework strategy applied here demonstrate the speaker's understanding about the social relationship and rules that she shares with the addressee.

The next example, which is cited from Haugh \& Obana (2011: p. 169), represents how an FTA can be implied by buffers only rather than actually uttered.

(7) 1. Assistant: 申し訳ございません...申し訳ございません ... excuse(POL)-have-POL-NEG excuse(POL)-have-POL-NEG

"I am very sorry ... I am very sorry."

2. Visitor: あ、いけない? 
oh acceptable-NEG

“oh, is this not allowed?”

3. Assistant: 申し訳ございません ...

excuse(POL)-have-POL-NEG

"I am very sorry."

According to Haugh \& Obana (2011), this is an interaction between an assistant at a museum in Tokyo and a visitor who is about to start eating something in the museum. The current study views this interaction as a good example of face-redressing strategy. Instead of uttering a direct request, order or warning, the assistant apologises to the visitor using the polite and formal version of “sorry” in its honorific form 申し訳ございません mooshiwake gozaimasen. By doing so, the assistant implies that she has to perform an FTA against her will, and that she respects the visitor's negative face. The honorific form she chooses is based on her understanding of the social norms and the relationship that she shares with the visitor in this particular interaction.

Based on the examples discussed above and the others observed in the data set, this research proposes a typical FTA model in Japanese as Figure 2.

The most often observed pragmatic devices in positions of "Pre FTA hedges" and "Post FTA excuses" include but not limited to expressions of:

Apology

e.g. sumimasen ga... "Excuse me but..."

shitsuree desu ga... "This is rude but..."

anoo... "uh..." (indicating hesitation or discretion)

Reason or background of the FTA

e.g. ... karadesu "because ..."

... ndesu "for you see ..."

The Japanese FTA model proposed above describes the actual process which Japanese speakers engage in when producing FTAs, and the necessity of utilising particular linguistic means. It reflects the fact that Japanese speakers quite often apologise or give a reason (or some background information) both before and after uttering an FTA. The pre FTA hedges normally function to indicate to the listener of what is about to occur so that an FTA can be delivered with as little "blunt force" as possible, while post FTA excuses express a justification of or the speaker's unwillingness to perform the FTA. Both pre FTA hedges and post FTA excuses act as a cushion to soften the impact of the FTA and signify the speaker's effort to protect each other's face. An interesting point needed to be emphasised is that, as shown in the previous examples, in the Japanese language, the actual FTA at times does not necessarily have to be uttered, but rather hinted at or implied by the pre FTA hedges and/or post FTA excuses. In addition, a speaker may choose to use both the pre FTA and post FTA facework expressions or only one of them, or it is also possible to put more than one cushion only before or only after the FTA.

It has been also observed from the data that silence can also be used to express oneself without uttering a FTA, as shown in the example below.

(8) Iku: Ano ne, iwanakya ikenai koto ga aru n desu. [SILENCE]

INT INT tell-NEG-CON wrong thing SUB there-is AUX COP-POL

"Well umm, I have something to tell you. [SILENCE]"

A deconstruction of the dialogue within the scene shows that the speaker uses ano ne ("well umm") and iwanakya ikenai koto ga aru n desu ("I have something to tell you") together with the silence at the beginning of the conversation as preFTA hedges. They form a signpost to the listener that an FTA is about to occur, and the speaker is trying to convey a message that “what I'm about to say is difficult”. During the scene where Example (8) is observed, although the FTA is omitted for dramatic effect, it is implied by context and the speaker's boyfriend then comes and hugs her during the silence and in the next scene we discover that she is pregnant with his child. Since silence is also a subject of studies of non-verbal communication and involves many issues that lie beyond the scope of this study, we focus on verbal FTAs in this paper, and leave issues of politeness related to silence for future studies.

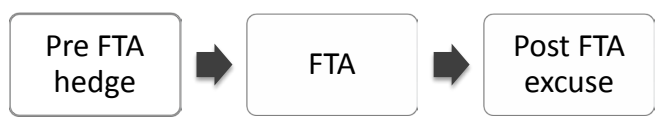

Figure 2. A typical FTA model in Japanese. 


\section{Conclusion}

By re-examining theories of linguistic politeness in Japanese and carefully analysing the data collected from recent Japanese TV dramas, this study confirms that, as a general principle, B \& L's $(1978,1987)$ theory of face does apply to Japanese language and culture and forms the basic factor of linguistic politeness. The actual facework and face redressive strategies in Japanese, however, show some unique features. By the word "unique", we do not simply mean that Japanese speakers need to act appropriately according to the social norm and their understanding or discernment of the social norm in order for an interaction to be successful, as this is in common with other cultures. We see the uniqueness of the Japanese as that their discernment (wakimae) and recognition of the social position and relationship (tachiba) of the participants, which form the second layer of the determining factors of politeness, make speakers of Japanese always attend to and try to fulfil the other participant's face wants including both positive and negative face, and, at the same time, maintain their own positive face but rarely claim their own negative face, especially when being the one with less power and a lower social position in an interaction. The data set of this study also suggests a model of face redressing strategies co-occurring with face threatening acts (FTA) in Japanese. That is, a pre-FTA hedge and/or a post-FTA excuse is needed almost all the time. In some extreme examples, the FTA itself can be omitted and implied by a pre-FTA hedge and/or a post-FTA excuse. This study holds that none of the existing theories alone can explicate Japanese linguistic politeness, as linguistic politeness is a very complicated issue influenced by multiple factors including general face want of participants, the participants' societal positions and social relationships (tachiba), social norm that the interactants share, the interactants' discernment or interpretation of the social rules (wakimae), immediate context of the interaction, and possible strategies for the interactants to choose under the constrains of the other simultaneously functioning factors. That is, linguistic politeness cannot be explicated from the viewpoint of any of these factors alone. All the factors need to be taken into consideration at the same time, and they must be seen as issues at different levels.

\section{Data Resources}

Onuma, Noriko (Writer). (2013). 真夜中のパン屋さん (Midnight Bakery) [TV drama]. Japan: NHK.

Sasaki, A., \& Furumaya, T (Writer). (2011). カレ、夫、男友達 (Boyfriend, Husband, Male Friend). [TV drama]. Japan: NHK.

Shibata, Yoshiki, \& Yoshida, Noriko (Writers). (2013). 激流〜私を憶えていますか (The Torrent: Do You Remember Me) [TV drama]. Japan: NHK.

\section{References}

Brown, P., \& Levinson, S. C. (1978, 1987). Politeness: Some Universals in Language Usage. Cambridge: Cambridge University Press.

Cook, H. M. (2006). Japanese Politeness as an Interactional Achievement: Academic Consultation Sessions in Japanese Universities. Multilingua, 25, 269-291. http://dx.doi.org/10.1515/MULTI.2006.016

Fukada, A. (2007). Nihongo yoorei, korokeishon joohoo chuushutsu shisutemu "Chakoshi” (Chakoshi: A Japanese Text Search and Collocation Extraction Application). Nihongo Kagaku (Japanese Linguistics), 22, 161-172.

Fukada, A., \& Asato, N. (2004). Universal Politeness Theory: Application to the Use of Japanese Honorifics. Journal of Pragmatics, 36, 1991-2002. http://dx.doi.org/10.1016/j.pragma.2003.11.006

Gagné, N. O. (2010). Reexamining the Notion of Negative Face in the Japanese Socio Linguistic Politeness of Request. Language \& Communication, 30, 123-128. http://dx.doi.org/10.1016/j.langcom.2009.12.001

Haugh, M. (2007). Emic Conceptulisations of (Im)politcncss and Face in Japanese: Implications for the Discursive Negotiation of Second Language Learner Identities. Journal of Pragmatics, 39, 657-680. http://dx.doi.org/10.1016/j.pragma.2006.12.005

Haugh, M., \& Obana, Y. (2011). Politeness in Japan. In D. Z. Kádár, \& S. Mills (Eds.), Politeness in East Asia (pp. 147-155). Cambridge: Cambridge University Press. http://dx.doi.org/10.1017/CBO9780511977886.009

Hill, B., Ide, S., Ikuta, S., Kawasaki, A., \& Ogino, T. (1986). Universals of Linguistics Politeness: Quantitative Evidence from Japanese and American English. Journal of Pragmatics, 10, 347-371. http://dx.doi.org/10.1016/0378-2166(86)90006-8

Ide, S. (1982). Japanese Sociolinguistics Politeness and Women’s Language. Lingua, 57, 357-385. http://dx.doi.org/10.1016/0024-3841(82)90009-2 
Ide, S. (1989). Formal Forms and Discernment: Two Neglected Aspects of Universals of Linguistic Politeness. MultilinguaJournal of Cross-Cultural and Interlanguage Communication, 8, 223-248. http://dx.doi.org/10.1515/mult.1989.8.2-3.223

Ide, S. (Ed.). (1992). Kotoba no Mozaiku [Mosaic of Language]. Tokyo: Japan Women’s University.

Ishiyama, O. (2009). A Note on Matsumoto Regarding Japanese Verbs of Giving and Receiving. Journal of Pragmatics, 41, 1061-1065. http://dx.doi.org/10.1016/j.pragma.2008.11.005

Kasper, G. (1990). Linguistic Politeness: Current Research Issues. Journal of Pragmatics, 14, 193-218. http://dx.doi.org/10.1016/0378-2166(90)90080-W

Lakoff, R. T. (1975). Language and Woman's Place: Text and Commentaries. New York: Harper \& Row.

Leech, G. N. (1983). Principles of Pragmatics. London, New York: Longman.

Mao, L. R. (1994). Beyond Politeness Theory: “Face” Revisited and Renewed. Journal of Pragmatics, 21, 451-486. http://dx.doi.org/10.1016/0378-2166(94)90025-6

Matsumoto, Y. (1988). Reexamination of the Universality of Face: Politeness Phenomena in Japanese. Journal of Pragmatics, 12, 403-426. http://dx.doi.org/10.1016/0378-2166(88)90003-3

Matsumoto, Y. (1989). Politeness and Conversational Universals-Observations from Japanese. Multilingua-Journal of Cross-Cultural and Interlanguage Communication, 8, 207-221. http://dx.doi.org/10.1515/mult.1989.8.2-3.207

Pizziconi, B. (2003). Re-Examining Politeness, Face and the Japanese Language. Journal of Pragmatics, 35, 1471-1506. http://dx.doi.org/10.1016/S0378-2166(02)00200-X

Sifianou, M. (1992). The Use of Diminutives in Expressing Politeness: Modern Greek versus English. Journal of Pragmatics, 17, 155-173. http://dx.doi.org/10.1016/0378-2166(92)90038-D 
Scientific Research Publishing (SCIRP) is one of the largest Open Access journal publishers. It is currently publishing more than 200 open access, online, peer-reviewed journals covering a wide range of academic disciplines. SCIRP serves the worldwide academic communities and contributes to the progress and application of science with its publication.

Other selected journals from SCIRP are listed as below. Submit your manuscript to us via either submit@scirp.org or Online Submission Portal.
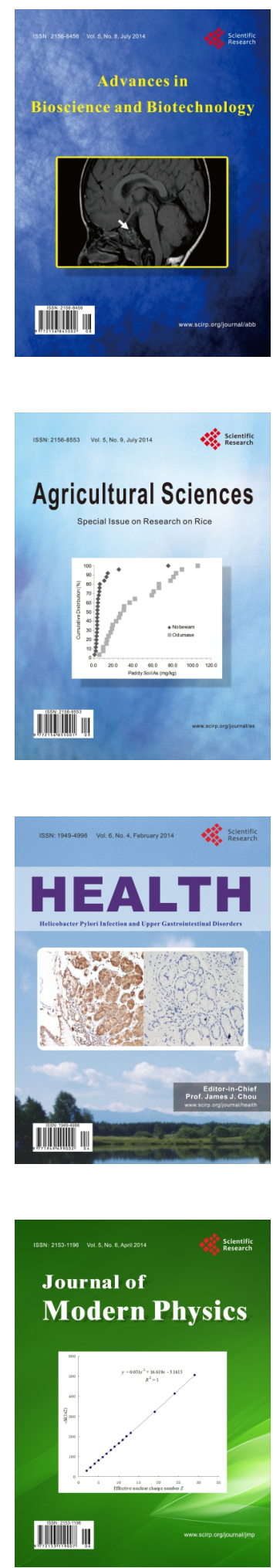
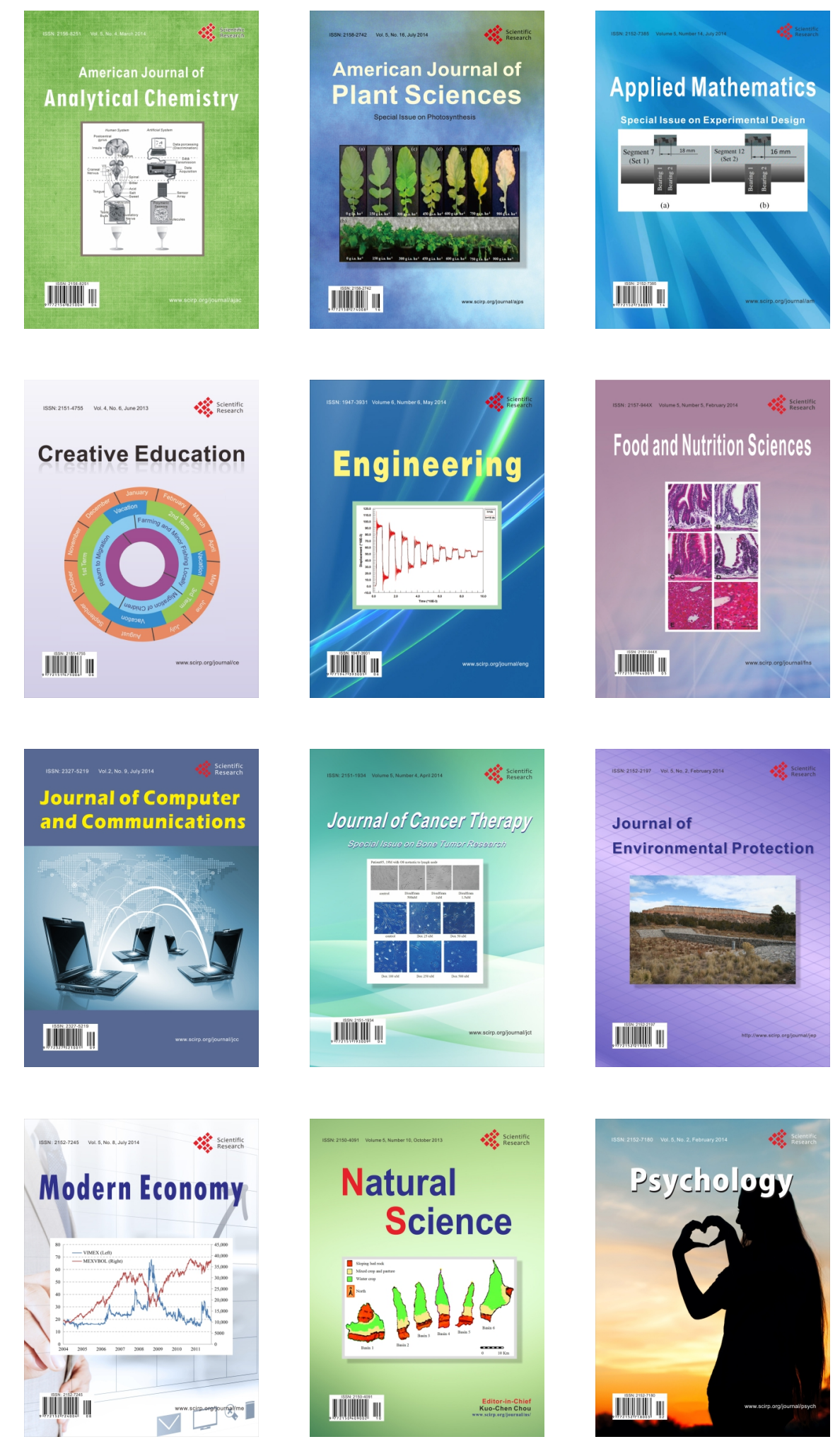